\title{
ANALYSING SOCIAL NEEDS AND SATISFACTORY LEVEL ON LIBRARY AND INFORMATION MANAGEMENT RECRUITMENT AT A MEKONG DELTA UNIVERSITY
}

\author{
Huynh Thi Trang ${ }^{1}$ \\ School of Social Sciences and Humanities, \\ Can Tho University (CTU), Vietnam \\ (Email: httrang@ctu.edu.vn) \\ Nguyen Nhu Huynh ${ }^{2}$ \\ School of Social Sciences and Humanities, \\ Can Tho University (CTU), Vietnam \\ (Email: huynhb1508379@ @student.ctu.edu.vn) \\ Le Vo Kieu Tran ${ }^{3}$ \\ School of Social Sciences and Humanities, \\ Can Tho University (CTU), Vietnam \\ (Email: tranb1508404@ student.ctu.edu.vn) \\ Ngo Thuy Linh ${ }^{4}$ \\ School of Social Sciences and Humanities, \\ Can Tho University (CTU), Vietnam \\ (Email: linhb1508381@student.ctu.edu.vn)
}

Accepted date: 23-04-2019

Published date: 17-07-2019

To cite this document: Huynh, T. T, Nguyen, H. N., Le, T. K. V., \& Ngo, L. T. (2019). Analysing Social Needs and Satisfactory Level on Library and Information Management Recruitment at a Mekong Delta University. International Journal of Modern Education, 1(1), 97-107.

DOI: $10.35631 /$ ijmoe. 11009

\begin{abstract}
This study presents social needs and satisfactory level on Library and Information Management recruitment and enrollment at Can Tho University, Vietnam from 2005 to 2018. The study used a quantitative approach and drew on secondary data provided by the Department of Academic Affairs through 14 years of university entrance exams and admission. Findings reveal that Can Tho University met $40 \%$ of the societal demands in the entrance examination period (2005-1014) and only 30.2\% at the admission phase (20152018). In the years 2006-2008, provinces such as Ca Mau, Hau Giang, and Vinh Long had a higher rate of successful candidates than that in other provinces in the Mekong Delta region and the number of female candidates was always at a much higher level than male candidates. Findings are necessary for the enrollment of Library and Information Management at Can Tho University and for other universities in terms of input evaluation. Implications are also presented with regard to making changes in admission quota.
\end{abstract}

Keywords: Admission Quota, Enrollment, Library and Information Management, Recruitment, Social Needs 


\section{Introduction}

In the era of innovation and integration, every industry in Vietnam requires huge human resources of high quality. Library and Information sector is not an exception because it is indispensable to have qualified staff to develop a long-term and sustainable library and information career. In 2005, Can Tho University conducted Library and Information Management training program to train librarians and information specialists to meet the societal needs promptly. It has been 14 years since it was officially put into operation, this training program has received many applications for entrance examination and admission. However, up to now, there has not been any research on the needs and the satisfactory level of this major through annual enrollment. This will inadvertently lose the overall view of the major's "supply" - "demand" level, which will not adjust, change admission quota, directly influence professional development of the major. Therefore, it is necessary to conduct a study to concretize social needs and satisfactory level of the major. The comparison of the number of candidates to register for the entrance exam, to be successful and to study officially every year will be of great significance. It will make a valuable reference source for high school students before registering this major in the university. This study will also lay a firm foundation for formulating new proposals to help the university board make feasible plans and changes of admission quota to align with the needs of high school students.

This study may benefit many parties. Firstly, high school students who are about to enter university will have a reliable source of information about the admission quota of the major, number of enrollments, and the ratio of application success each year in order to decide appropriate major. Secondly, the study will help the university and its Library and Information Management sector in particular articulate their goals and objectives to accomplish their training missions. Moreover, they will have plans and possible changes to tailor their quota for the enrollments of this major in coming years so as to best meet the aspirations of high school students. Thus, it is possible to become a good reference source for other universities and colleges worldwide in terms of input admission and evaluation.

\section{Problem Statement}

The tertiary program on Library and Information Management at Can Tho University is known as the most prestigious program in the Mekong Delta, Vietnam. It was established under the sponsor of the Atlantic Philanthropies (USA) in 2005. The textbooks of this program were compiled by faculties and information specialists from USA, Australia, New Zealand, Singapore, Malaysia and Vietnam. Furthermore, students graduating from this program are highly appreciated by the recruiters and employers inside and outside the country. Therefore, hundreds of high school students have been attracted to register and enrol into this program every year. However, till now there has been no research to identify and analyse the enrolment, percentage of admission and admitted ratio by gender or hometown as well as the satisfactory level in each recruitment period. This study therefore fills this gap and creates a valuable resource for high school students in making decisions to choose the training program.

\section{Literature Review}

Every educational system in the world has its own way to recruit qualified students to school, college or university. In Western countries such as the United States, universities and colleges select their native students based on many criteria including standardised tests scores. They include the Scholastic Achievement Test (SAT)- testing English and Mathematics, the American College Test (ACT) - testing English, Mathematics, Reading 
Comprehensions and Science, academic performance in high schools (GPA and transcripts), essays, recommendations, and any additional evidence about special talents or student experiences. The United States has 3,000 universities and 1,700 community colleges, which can receive over 4 million students annually. The number of high school graduates every year is about 3.3 million (1\% of the population). In fact, the US universities accept all native students and receive about 100 thousand non-native students yearly (Tran, 2015) approximately 70 percent of all international students (Choudaha, 2015). To meet admission, the international students have to take the standardised admission tests such as GRE, GMAT and SAT as well as English language tests namely TOEFL and IELTS. Majority of successful candidates to universities and colleges are from big cities and suburban areas. Therefore, many counties have privilege policies to attract more candidates from distant and rural regions. For example, top universities in Georgia such as Georgia Institution of Technology, Emory University, and University of Georgia seek more undergraduate students from rural areas. This decision has been made because only 4.8; 8.1 and 12.2 percent of these respective university populations are from rural counties in the 2017 academic year (Stirgus, 2018). In Latin American countries, the gross enrollment ratios decrease from 84 percent in Chile, 80 percent in Argentina to 46 percent in Brazil in 2013 (Gayardon, 2017). Different from other South American countries, Argentina has conducted an easy-to-enter mechanism into university. Rabossi (2013, p. 23) stated "During the presidency of Juan Domingo Perón (1946-1955), Argentina implemented an open-admissions policy for all public universities. All aspirants holding a secondary degree were admitted". In 2010, this country enrolled $79.5 \%$ high school students to higher education and each university is free to determine its own admissions process. In France, students must take the only exam to graduate from high school and enroll in university and college, called the Baccalaureate. Students must achieve a minimum of 10/20 points (averaging the points of subjects). If they score only 8-9/20, they will have to retake the exam or an oral exam later. If the students gain below $8 / 20$, they must re-study (Le, 2018). In Turkey, colleges and universities recruit their students based on the scores of the Transition to Higher Education Examination (YGS) in Turkish. This exam paper consists of 40 questions in literature, 40 in social sciences, 40 in mathematics and 40 in science (Celik \& Koc, 2015). As an Asian country, Armenia has around 3 million inhabitants. The gross enrollment ratio in tertiary education is 44.31 percent (Gharibyan, 2017). Likewise, Iranian public universities recruit only 10 percent of high school students every year (Kamyab, 2015) and Ethiopian gross enrollment ratio is 10.2 percent (Woldegiyorgis, 2017). Similarly, criteria to select qualified students to enter universities in Iran are known as the cumulative grade-point average (GPA) of the final three years of high school, interviews, essay writing, and aptitude tests. Quite different from these countries, high growth rates have seen tertiary enrollments in Mongolia increase dramatically from 14 percent in 1990s to 68 percent in 2015 (Loo, 2017).

In several South-East Asian countries, all qualified students are selected by a uniform national university entrance examination. The ratio of gross enrollment is different from country to country. For example, it is only 10 percent of high school students in Myanmar present in universities and colleges while this ratio reaches 87 percent in Singapore, Thailand (50\%), Malaysia (37\%), and Indonesia (32\%), and Myanmar, Cambodia, and Laos are all under 20 percent (Altbach, 2017). Recently, Chinese educational system has reformed following American style. Equivalent to the SAT or ACT tests, students in China have to sit in the standardized test scores in Mathematics, Chinese Language, and English plus three elective subjects. The learning process in high school is assessed by standardized tests after completing each course. All courses included in the general education program are counted, while in the old way, the new educational system exam covers only a few subjects. The new 
approach will show a more comprehensive picture of the learning process, just like the GPA average in the US system. However, instead of essays and letters of recommendation as in the US system, China's reforming system takes into account the " assessment of comprehensive capacity" - an important set of records on activities, demonstrating moral qualities (love of the Party, patriotism, ideals, honesty and reliability, kindness and friendliness, responsibility, understanding of law and discipline), learning counselling, mental and physical health, aptitude/ artistic talents, level of engagement with the community and society (Ly Nga \& Tran, 2015).

Quite different from these mentioned countries, Vietnam responds to meeting the students' higher education study based on entrance examinations or selection of qualified students from top down to definite admission quota. Currently, Vietnam has 400 public universities receiving about 400,000 students and 20 percent private institutes with 15 percent of high school students' enrollment annually (Nguyen, 2016). The number of high school graduates every year is about one million ( $1.1 \%$ of the population). Consequently, about 600,000 students could not continue to higher education after graduating from their high school (Tran, 2015). Vietnamese government has issued various documents and guidelines on university examinations with different form of admissions through period of time. In particular, before 1970, candidates graduated from high schools did not take university exams. Instead, they were considered for admission based on their background. From 1970 to 1980, candidates participated in the local university entrance exams organised by the Ministry of Education and Training (MoET). Candidates were assigned to universities when they were admitted. From 1980 to 1990, high school graduation exam and university exam were separated. Candidates only register for only one university. With university entrance exam, qualified students for each major were selected based on scores of each block of academic subjects. For example, block A is the combination of Maths - Physics - Chemistry, block B with Maths - Chemistry - Biology, block C with Literature - History - Geography, block D with Literature - Maths - Foreign language, and so on. From 1990 to 2001, Vietnam applied a high school graduation exam, 02 university exams and 01 college exam. Each university makes its own examination based on the guidelines of the MoET. From 2002 to 2014, the MoET organized the national exam for all high school students. This exam was known with 3 common criteria: the same exam questions, the same examination dates and periods, and shared the national exam results. During this time, the MoET organized one high school graduation exam, one university exam consists of two phases for different exam blocks, and one college exam. Each university uses the exam results of the Ministry to recruit students. Also indicated from 2014, the MoET used "floor marks" (minimum entrance exam points) to indicate the required points in the number of admission marks. This means that only students with their exam scores equal or higher than "floor marks" will officially be considered for selection. From 2015 to the present, the MoET has applied the form of admission to universities and colleges based on the results of high school graduation exam according to Circular No. 02/2015/TT-BGDĐT dated 26/5/2015. The MoET conducts exams with 8 subjects such as Maths, Literature, History, Geography, Physics, Chemistry, Biology, Foreign languages. Universities and colleges use scores according to the exam block to select qualified students. Since 2017, Vietnamese universities and colleges have possessed their autonomy and self-responsibility in enrollment (Pham, 2014). Most recently, Circular No. 06/2018/TT-BGDĐT of MoET was issued on February 28, 2018 to regulate the determination of admission quota for intermediate and college levels on teacher training disciplines, bachelor, master and doctoral qualifications. The Circular specifies the number of enrollments calculated according to the number of permanent teachers, physical facilities and equipment; and market demand and socio-economic development needs (Ministry of 
Education and Training, 2018). Currently, the proportion of tertiary enrollments of the private higher education sector is about 10 percent. With this new Circular, it proposes that this ratio be 40 percent by 2020. Furthermore, student enrollments of public universities and colleges will be three to four times larger than those at present (Hayden \& Lam, 2006).

\section{Conceptual Framework}

According to Chapman (1981) need is defined as the nature of the living organism, expressing the state of deficiency of the individual itself and thus distinguishing it from the living environment. The minimum need, or absolute need, has been programmed through a very long process of survival, development and evolution. Meanwhile, Kotler (2003) indicates that individuals' needs refer to the feeling of missing something that people feel. Such feelings occur when a person identifies deficiency to be satisfied and compensated. In this current paper, societal needs are the high school students' needs to pursue their universities and thus these needs can be measured by the number and percentage of annual registrations.

In this research context, satisfaction is defined as fulfilling expectations or needs (Oxford University, 2012). Satisfactory level can be understood as how much it is in fulfilling all demands or requirements. Thus, satisfactory level on societal needs is identified by percentage of high school students' registrations compared to admission quota and the percentage of enrollments (the actual number of high school students) to study at the universities. The proposed conceptual framework is illustrated in Figure 1.

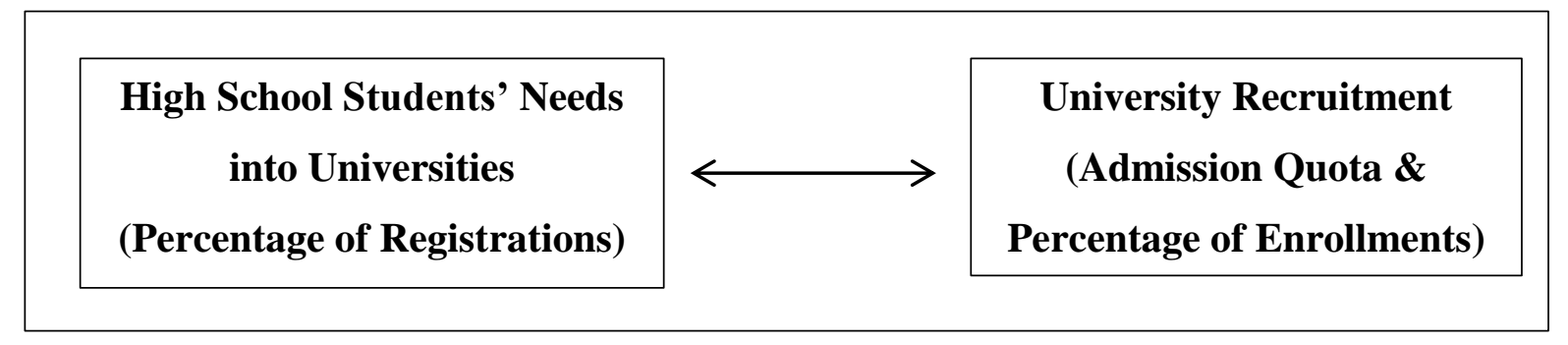

Figure 1: Proposed Conceptual Framework

\section{Research Objectives}

The objective of this study is to identify the percentage of high school students' needs and their satisfactory level on Library and Information Management recruitment. The specific objectives are as follows:

1. Identifying the percentage of high school students' registration, admission quota and percentage of enrolments in Library and Information Management bachelor program

2. Analysing the satisfactory level on high school students' needs to study in Library and Information Management bachelor program

\section{Methodology}

This study was conducted using quantitative research method based on statistics of registrations and enrollments at Can Tho University from 2005 to 2018. Raw data was provided by Can Tho University's website and the Department of Academic Affairs. Statistical data include names, hometowns, gender and total scores of the candidates. Then, data was aggregated into the number of students sitting in the exam, the admission quota, the number of students enrolled, and the number of male-female students admitted each year. In the following step, data was put into Excel to compare the difference by gender, hometown and school year. Because there has been a change in enrollment form (admissions instead of 
entrance examinations), the comparison method was also different. Quantitative data was analysed by percentage of enrollment, percentage of admission and admitted ratio by gender. The results of the research will be the basis and premise for the assessment of the needs and the satisfactory level in the enrollment of Library and Information Management. Thereby the appropriate changes and supplements will be formed to meet the academic needs of the society.

\section{Research Findings}

Data of 14 years of registrations and enrollments on Library and Information Management was analysed by gender, hometown and the satisfactory level. Results were shown into 2 phases (2005-2014 and 2015-2018). It is because there has been a change in the form of university admissions since 2015. In particular, based on Circular No. 02/2015 / TT-BGDĐT of the Ministry of Education and Training on promulgating regulations on national high school examination and criteria to graduate, high school students use the results of the National High School graduation exam to register into universities and colleges instead of sitting in two separate exams.

\section{Satisfactory Level During Entrance Exam Period (2005 - 2014)}

Data of Table 1 shows that the number of candidates preferring Library and Information Management as their major varies from year to year. In average, there are 200 candidates a year. However, the first year of entrance examination period (in 2005) was known with the highest number of registrations with 462 candidates. The lowest number in 2010 was only 93 candidates. The total number of candidates from 2005 to 2014 was 1,992 contestants.

Data in Table 1 also indicates that within 10 years of applying entrance examination, aspirations of high school students are higher than those of the major. In 2012, the highest satisfactory level (132 students) with $86.8 \%$ was due to the relatively low number of registrations (152 candidates). The year that met the lowest demand was 2005 with $13 \%$ due to the highest number of registered candidates (462 candidates). On average, the satisfactory level of the major is about $40 \%$, which is at a relative level. The satisfactory level tends to decrease significantly since 2010 (from $83.9 \%$ to $36.5 \%$ in 2011, from $86.8 \%$ in 2012 to $32.8 \%$ and $34.3 \%$ in 2013 and 2014 respectively) with the consistent quota of 60 throughout the years to come. In 2009, the number of successful candidates (42 students) was lower than the quota (60). This proves that the demand of society and high school students has increased significantly, and the major could not meet timely.

In addition, the number of students enrolled in Library and Information Management from 2005 to 2014 has always changed over the years. The year with the highest number of students enrolling was in 2010 with 77 students compared to the successful admission was 78 (with 97.8\%). Ranking second in terms of enrollment was in the year 2006 with 60 students out of 66 admissions (with 90.9\%). The third place was in the year 2008 with 38 students out of 42 admissions (with 90.5\%). The lowest enrollment was in the year 2014 with 53 students out of 105 admitted students (with 50.5\%). In general, the number of students enrolling is always lower than the number of candidates admitted. This proves that in terms of enrollment, the major always meet the candidate's needs of higher education.

In terms of gender, 10 years of entrance examination has been always seen that the number of successful female candidates (520 students) was nearly 5 times higher than that of male candidates (115 students). More specifically, the number of successful female candidates reached to $86.7 \%$ (52 students per year on average). Meanwhile, the number of male 
candidates was $13.3 \%$ (12 students per year on average). The highest number of male candidates was 20 in the year 2013, the lowest was 5 in the year 2007 and 2008. The highest number of female candidates was in the year 2008 with 57 students, the second highest was 47 in the year 2007, and the lowest was in the year 2009 with 32 ones.

Table 1: Entrance Exam Period (2005-2014)

\begin{tabular}{cccccccccccc}
\hline \multirow{2}{*}{ Year } & \multirow{2}{*}{ Candidates } & \multicolumn{2}{c}{ Quota } & \multicolumn{2}{c}{ Admission } & \multicolumn{2}{c}{ Enrollment } & \multicolumn{2}{c}{ Male } & \multicolumn{2}{c}{ Female } \\
\cline { 2 - 11 } & & $\mathbf{n}$ & $\boldsymbol{\%}$ & $\mathbf{n}$ & $\mathbf{\%}$ & $\mathbf{n}$ & $\mathbf{\%}$ & $\mathbf{n}$ & $\mathbf{\%}$ & $\mathbf{n}$ & $\boldsymbol{\%}$ \\
\hline $\mathbf{2 0 0 5}$ & 462 & $\mathbf{4 0}$ & $\mathbf{8 . 7}$ & $\mathbf{6 0}$ & $\mathbf{1 3 . 0}$ & 49 & 81.6 & 12 & 24.5 & 37 & 75.5 \\
\hline $\mathbf{2 0 0 6}$ & 127 & 60 & 47.2 & 66 & 52.0 & $\mathbf{6 0}$ & $\mathbf{9 0 . 9}$ & 8 & 13.3 & 52 & 86.7 \\
\hline $\mathbf{2 0 0 7}$ & 144 & 70 & 48.6 & 72 & 50.0 & 52 & 72.2 & $\mathbf{5}$ & 9.6 & $\mathbf{4 7}$ & 90.4 \\
\hline $\mathbf{2 0 0 8}$ & 121 & 70 & 57.9 & 79 & 65.3 & 62 & 78.5 & $\mathbf{5}$ & 8.1 & $\mathbf{5 7}$ & 91.9 \\
\hline $\mathbf{2 0 0 9}$ & 117 & 60 & 51.3 & $\mathbf{4 2}$ & $\mathbf{3 5 . 9}$ & $\mathbf{3 8}$ & $\mathbf{9 0 . 5}$ & 6 & 15.8 & $\mathbf{3 2}$ & 84.2 \\
\hline $\mathbf{2 0 1 0}$ & 93 & $\mathbf{6 0}$ & $\mathbf{6 4 . 5}$ & $\mathbf{7 8}$ & 83.9 & $\mathbf{7 7}$ & $\mathbf{9 8 . 7}$ & 12 & 15.6 & 65 & 84.4 \\
\hline $\mathbf{2 0 1 1}$ & 208 & 60 & 34.5 & 76 & 36.5 & 67 & 88.1 & 12 & 17.9 & 55 & 82.1 \\
\hline $\mathbf{2 0 1 2}$ & 152 & 60 & 45.5 & $\mathbf{1 3 2}$ & $\mathbf{8 6 . 8}$ & 103 & 78.0 & 25 & 24.3 & 78 & 75.7 \\
\hline $\mathbf{2 0 1 3}$ & 262 & 60 & 26.9 & 86 & 32.8 & 73 & 84.9 & $\mathbf{2 0}$ & 27.4 & 53 & 72.6 \\
\hline $\mathbf{2 0 1 4}$ & 306 & $\mathbf{6 0}$ & $\mathbf{2 2 . 2}$ & $\mathbf{1 0 5}$ & $\mathbf{3 4 . 3}$ & $\mathbf{5 3}$ & $\mathbf{5 0 . 5}$ & 10 & 17.0 & 44 & 83.0 \\
\hline Total & $\mathbf{1 . 9 9 2}$ & $\mathbf{6 0 0}$ & & $\mathbf{7 9 6}$ & & $\mathbf{6 3 4}$ & & $\mathbf{1 1 5}$ & $\mathbf{5 2 0}$ & \\
\hline Average & $\mathbf{2 0 0}$ & $\mathbf{6 0}$ & $\mathbf{3 0 . 0}$ & $\mathbf{8 0}$ & $\mathbf{4 0 . 0}$ & $\mathbf{6 4}$ & $\mathbf{8 0 . 0}$ & $\mathbf{1 2}$ & $\mathbf{1 3 . 3}$ & $\mathbf{5 2}$ & $\mathbf{8 6 . 7}$ \\
\hline
\end{tabular}

(Source: Department of Academic Affairs, Can Tho University)

\section{Satisfactory Level during Admission Phase (2015 - 2018)}

As mentioned above, starting from 2015, the form of enrollment has changed so the candidates will submit their application for admission after obtaining the results of the National High School Exam. According to data from Table 2, the year 2018 had the highest number of successful candidates, 140 candidates and the year with the lowest number of candidates was 2017 with 73 candidates. The total number of successful candidates from 2015 until now is 315 candidates. In terms of gender, similar to the entrance examination period, the successful female candidates were with a larger number than male candidates. The highest number of female candidates was in the year 2018 with 77 candidates, the lowest was in the year 2017 with 40 candidates. In 2017, the highest number of male candidates was 20 and the lowest was 13 candidates in 2018.

Regarding the quota of the major, admission quota of this period has increased relative to that of the entrance examination period with an average of 78 quota per year. With this quota, the major only meets $24.8 \%$ of the society's needs. In terms of matriculation results, the year with the highest percentage of matriculation was in 2016. There were 86 students selected 
compared to 142 candidates registered for admission, meeting $60.6 \%$ of the society's needs. The year 2017 was considered as the year with the lowest satisfactory level of 73 students with $24.4 \%$. In 2018, selection quota of the major was 80 candidates while 140 students were admitted. However, because the number of registrations was too high (509 candidates), although the university has increased the selection quota of 60 more students, the satisfactory level was only with $27.5 \%$. In terms of enrollment results, the year with the highest number of students enrolling was in 2015 with 79 students compared to 80 students matriculated (96.3\%). In contrast, the lowest number of students enrolled in this major out of 4 years of university admission was in 2018 with 90 students compared to 140 students, reaching $64.3 \%$. In general, in the stage of admission to university, this major satisfied only $30.2 \%$ of the demand of the society. This satisfactory rate decreased by nearly $10 \%$ compared to the entrance examination period of $40 \%$.

Table 2. Admission Period (2015-2018)

\begin{tabular}{cccccccc}
\hline \multirow{2}{*}{ Year } & \multirow{2}{*}{ Registration } & \multicolumn{2}{c}{ Quota } & \multicolumn{2}{c}{ Admission } & \multicolumn{2}{c}{ Enrollment } \\
\cline { 3 - 8 } & & $\mathbf{n}$ & $\mathbf{\%}$ & $\mathbf{n}$ & $\mathbf{\%}$ & $\mathbf{n}$ & $\mathbf{\%}$ \\
\hline 2015 & 310 & 80 & 25.8 & 82 & 26.5 & $\mathbf{7 9}$ & $\mathbf{9 6 . 3}$ \\
\hline 2016 & 142 & $\mathbf{7 0}$ & $\mathbf{4 9 . 3}$ & $\mathbf{8 6}$ & $\mathbf{6 0 . 6}$ & 64 & 74.4 \\
\hline 2017 & 299 & 80 & 26.8 & $\mathbf{7 3}$ & $\mathbf{2 4 . 4}$ & 63 & 86.3 \\
\hline 2018 & 509 & $\mathbf{8 0}$ & $\mathbf{1 5 . 7}$ & 140 & 27.5 & $\mathbf{9 0}$ & $\mathbf{6 4 . 3}$ \\
\hline Average & $\mathbf{3 1 5}$ & $\mathbf{7 8}$ & $\mathbf{2 4 . 8}$ & $\mathbf{9 5}$ & $\mathbf{3 0 . 2}$ & $\mathbf{7 4}$ & $\mathbf{7 7 . 9}$ \\
\hline
\end{tabular}

(Source: Department of Academic Affairs, Can Tho University)

In general, through both phases of enrollment (entrance exam and admission), the admission quota of Library and Information Management sector always fluctuates in the range of 60 80. Particularly, selection quota of candidates in the year 2005 was only 40 . The number of students enrolled in this major is always stable over the years and tends to be increased. That shows the increasing demand of society. Meanwhile, the satisfactory level is decreasing. On average, the annual satisfactory level in the entrance exam period is $40 \%$ and the ratio of the admission stage is only 30.2\%. In comparison with other countries in South-East Asia, Vietnam satisfies only $20 \%$ of social requirements to study in the university. In the meanwhile, Singapore scored the first with 87\%, Thailand 50\%, Malaysia 37\% and Mynamar $10 \%$ (Altbach, 2017). Therefore, the satisfactory level of Library and Information Management program is $10 \%$ to $20 \%$ higher than the average level of the whole country. Compared to other countries in the world, Vietnam is in the group of low satisfactory level to high school students' requirements to university. Other countries such as Chile gains $84 \%$, Argentina 80\% (Gayardon, 2017), Mongolia 68\% (Loo, 2017), etc. The number of male and female students is also relatively large in the entrance exam period. The ratio of male candidates is always 5 times lower than the number of female candidates. This issue needs to be considered. Attracting the attention and interest of male students should be promoted to balance the number of candidates as well as official students.

\section{Candidates by Hometown}

Data of the candidates' hometowns in 03 years 2006, 2007 and 2008 were also analysed. According to the figures in Table 3, the candidates mainly come from all 13 provinces in the Mekong Delta and a few come from the central provinces of the country. Of the 784 candidates from the Mekong Delta region, contestants from Can Tho City (the biggest city in the Mekong Delta) always accounted for the highest number of 79 candidates. Next is the 
contestant from Vinh Long with 67 contestants, Hau Giang with 45 candidates and Ca Mau with 34 candidates. The provinces with the lowest number of candidates are Bac Lieu (8 candidates) and Long An (7 candidates). Thus, the neighbouring provinces of Can Tho city always score the highest number of contestants because of the short travel distance. In particular, this major has also attracted candidates from 3 central provinces. That is a male contestant who came from Binh Duong in 2007; Dak Nong and Quang Tri each has 1 female contestant in 2008. In addition, the number of male and female is also different. Specifically, the highest number of female candidates from Can Tho is 62 students. The lowest is Bac Lieu and Long An with the number of female candidates is 7 and 6 respectively. The province has the highest number of male candidates is Can Tho with 17 candidates. In general, regardless of the province, the number of females is always higher than the number of male candidates. This finding re-affirms that high school students from big cities and suburban regions get more opportunities to achieve higher education than those from rural and distant ones.

Table 3: Candidates by Hometown

\begin{tabular}{|c|c|c|c|c|c|c|c|c|c|c|}
\hline \multirow{2}{*}{ Province } & \multicolumn{3}{|c|}{2006} & \multicolumn{3}{|c|}{2007} & \multicolumn{3}{|c|}{2008} & \multirow{2}{*}{ Tota } \\
\hline & $\mathbf{n}$ & Male & Female & $\mathbf{n}$ & Male & Female & $\mathbf{n}$ & Male & Female & \\
\hline An Giang & 5 & 1 & 4 & 3 & 1 & 2 & 6 & 0 & 6 & 14 \\
\hline Bac Lieu & 3 & $\mathbf{0}$ & 3 & 3 & 1 & 2 & 2 & $\mathbf{0}$ & 2 & 8 \\
\hline Ben Tre & 5 & 1 & 4 & 8 & 2 & 6 & 7 & 1 & 6 & 20 \\
\hline Ca Mau & 14 & $\mathbf{0}$ & 14 & 14 & $\mathbf{0}$ & 14 & 6 & 0 & 6 & 34 \\
\hline Can Tho City & 26 & 10 & 16 & 36 & 6 & 30 & 17 & 1 & 16 & 79 \\
\hline Dong Thap & 8 & 0 & 8 & 8 & 1 & 7 & 10 & 1 & 9 & 26 \\
\hline Hau Giang & 14 & 1 & 13 & 12 & 2 & 10 & 19 & 7 & 12 & 45 \\
\hline Kien Giang & 5 & 0 & 5 & 9 & 0 & 9 & 9 & 2 & 7 & 23 \\
\hline Long An & 3 & 0 & 3 & 4 & 1 & 3 & & & & 7 \\
\hline Soc Trang & 10 & 1 & 9 & 8 & 0 & 8 & 10 & 1 & 9 & 28 \\
\hline Tiền Giang & 11 & 1 & 10 & 4 & 1 & 3 & 5 & 0 & 5 & 20 \\
\hline Tra Vinh & 6 & 1 & 5 & 8 & 2 & 6 & 4 & 2 & 2 & 18 \\
\hline Vinh Long & 17 & 4 & 13 & 26 & 5 & 21 & 24 & 7 & 17 & 67 \\
\hline Binh Duong & & & & 1 & 1 & 0 & & & & 1 \\
\hline Dak Nong & & & & & & & 1 & 0 & 1 & 1 \\
\hline Quang Tri & & & & & & & 1 & 0 & 1 & 1 \\
\hline
\end{tabular}




\begin{tabular}{lllllllllll}
\hline Total & 127 & 20 & 107 & 144 & 23 & 121 & 121 & 22 & 99 & 784
\end{tabular}

(Source: Department of Academic Affairs, Can Tho University)

These research findings help the Department of Library and Information Management and Can Tho University to identify and satisfy the actual social needs on higher education. Based on the social needs and satisfactory level of each year, the university may re-consider the admission quota so as to meet the increasing aspirations of the high school students. Universities and colleges should create more opportunities for high school students who want to be well-educated citizens of the nation.

\section{Conclusion}

Today, choosing the appropriate discipline plays a vital role for an individual's career path. To choose the right school and right career, candidates need appropriate advice and reliable source of information. Effective consultancy for high school students helps them choose the right university and the right major that fits well with their aspirations, interests, learning capacities and human resource demands. To respond to the global competition and increasing societal development, competition in enrollment also becomes more challenging. Can Tho University is no exception. Enrollment requires qualified candidates. Library and Information Management sector of Can Tho University with 19 years of operation has been constantly developing and getting more and more attention from the community. Research findings reveal that Library and Information Management program at Can Tho University meets $40 \%$ of the societal demands in the entrance examination period (2005-1014) and only $30.2 \%$ at the admission phase (2015-2018). The satisfactory level of high school students' needs is $10 \%$ to $20 \%$ higher than the average level of the whole country and so much lower than those of other countries in the world. The ratio of female candidates is always 5 times higher than the number of male candidates. This research contributes to the understanding of the pertinent major in university enrolment with regard to identifying societal demands and satisfactory level of higher education learning needs.

Library and Information Management sector and Can Tho University should consider proper policies to attract candidates in order to reduce the disparity in sex imbalance. In addition, when conducting propaganda, counselling to enrollment for high school students should strengthen and pay more attention to promoting the image of the major to attract more male students. University should think of privilege policies and scholarship supports for students. Another potential way is also given to the adjustment of selection quota so that the number of candidates who wish to enter this major increase.

\section{References}

Altbach, P. G. (2017). The Complex Diversity of Southeast Asian Postsecondary Education. International Higher Education, 88(4), 16-18.

Celik, B., \& Koc, N. (2015). Effect of Class Size on University Entrance Exam in Turkey. Procedia - Social and Behavioral Sciences, 191, 919-924.

Chapman, D. W. (1981). A Model of Student College Choice. The Journal of Higher Education, 52(5), 490-505. doi: 10.1080/00221546.1981.11778120

Choudaha, R. (2015). International Student Enrollment: Evidence-Driven Strategies. International Higher Education, 79(4), 20-21.

Gayardon, A. d. (2017). Free Higher Education: Mistaking Equality and Equity. International Higher Education, 91(3), 12-13. 
Gharibyan, T. (2017). Armenia: Cross-Border Higher Education. International Higher Education, 91(3), 6-8.

Hayden, M., \& Lam, Q. T. (2006). A 2020 Vision for Higher Education in Vietnam. International Higher Education, 44(2), 11-13.

Kamyab, S. (2015). The University Entrance Exam Crisis in Iran. International Higher Education(51), 22-23. doi: 10.6017/ihe.2008.51.8010

Kotler, P. (2003). Makerting Management. Upper Saddle River, N.J.: Prentice Hall.

Le, T. N. (2018). Sau Nam 2020, Viet Nam Se Tuyen Sinh Dai Hoc Theo Huong Nao? [After 2020, Which Direction Will Vietnam Enroll Students?]. Retrieved March 10, 2019, from https://anninhthudo.vn/chinh-tri-xa-hoi/sau-nam-2020-viet-nam-se-tuyen-sinhdai-hoc-theo-huong-nao/787742.antd

Loo, B. (2017). Mongolia: Higher Education and Mobility. International Higher Education, 89(1), 19-21.

Ly Nga, \& Tran, L. T. (2015). Trung Quoc Cai Cach Tuyen Sinh Dai Hoc Theo Phong Cach My [China Reforms University Enrollment as American Style]. Tia Sang [Light], 21, 44-47.

Ministry of Education and Training. (2018). Thong Tu So 06/2018/TT-BGDĐT Quy Dinh Ve Viec Xac Dinh Chi Tieu Tuyen Sinh Trinh Do Trung Cap, Cao Dang Cac Nganh Dao Tao Giao Vien; Trinh Do Dai Hoc, Thac Si, Tien Si [Circular No. 06/2018/TTBGDĐT Determinates Criteria for Enrollment of Intermediate and College Levels of Teacher Training Disciplines; Bachelor, Master and Doctoral Qualifications]. Ha Noi, Viet Nam: Ministry of Education and Training.

Nguyen, D. T. H. (2016). Private Higher Education in Vietnam: Issues of Governance and Policy. International Higher Education, 87(3), 22-24.

Oxford University. (Ed.) (2012). Oxford English Dictionary. London: Oxford University Press.

Pham, V. L. (2014). Doi Moi Giao Duc Dai Hoc Va Cong Tac Thi, Tuyen Sinh Dai Hoc, Cao Dang [Innovating Higher Education and Examination, University and College Enrollment]. Tap chi Giao duc [Journal of Education], 1(326), 1-3.

Rabossi, M. (2013). Argentine Public Universities: Inefficient and Ineffective? International Higher Education, 71(1), 23-24.

Stirgus, E. (2018). AJC Digging Deeper Education: Top Georgia Universities Seek More Rural Students: Georgia Tech, Emory, UGA Launch Efforts to Boost Recruitment. The Atlanta Journal - Constitution.

Tran, T. (2015). So Sanh Tuyen Sinh Dai Hoc Cua My Va Viet Nam [Comparison of Higher Education Recruitment between the USA and Vietnam]. Day va Hoc ngay nay [Teaching and Learning Today], 11, 8-9.

Woldegiyorgis, A. A. (2017). The Vicious Circle of Quality in Ethiopian Higher Education. International Higher Education, 90(2), 18-19. 